More Information

\section{Psychotropic drugs prescription block the positive effects of the doctor-patient communication and relationship}

\author{
Jose Luis Turabian*
}

Specialist, Family and Community Medicine, Health Center Santa Maria de Benquerencia, Regional Health Service of Castilla la Mancha (SESCAM), Toledo, Spain

\section{Abstract}

The fact that general practitioner (GP) or psychiatrist understands the psychosocial effects of prescribing on the doctor-patient relationship is as important, if not more so, than knowing pharmacology. Any prescription of drugs modifies the doctor-patient relationship. Drugs, especially psychotropic drugs, act on symptoms and change thoughts, feelings, and behaviors; they can create both physical and psychological dependency; they can discourage a deep search for real solutions, both on the part of the doctor and the patient; they can affect the doctor's access to the patient and the problem will be out of their reach. Psychotropic drugs can make the effect of the doctor in himself as a drug more difficult, favor an insignificant or problematic or little human relational context, where the GP/psychiatrist does not delve into the true meaning of the symptoms, and the patient tends not to get involved, to make an emotional withdrawal, to be passive before the prescribed drug, and can result in the chronification and structuring of functional symptoms that become organic, with lack of cooperation of the doctor and the patient, and paradoxically with over-compliance or therapeutic discontinuity and the lack of pharmacological adherence, absences to appointments or delays or cancellations of visits, and the denial of responsibility of both the doctor and the patient.

\author{
*Address for Correspondence: \\ Jose Luis Turabian, Health Center Santa Maria \\ de Benquerencia Toledo, Spain, \\ Email: jturabianf@hotmail.com \\ Submitted: December 23, 2020 \\ Approved: February 17, 2021 \\ Published: February 18, 2021 \\ How to cite this article: Turabian JL. \\ Psychotropic drugs prescription block the \\ positive effects of the doctor-patient \\ communication and relationship. Arch Psychiatr \\ Ment Health. 2021; 5: 014-017.
}

\section{DOI: 10.29328/journal.apmh.1001029}

Copyright: (c 2021 Turabian JL. This is an open access article distributed under the Creative Commons Attribution License, which permits unrestricted use, distribution, and reproduction in any medium, provided the original work is properly cited.

Keywords: Physician-patient communication; Inappropriate prescribing; General practice; Psychotropic drugs

Check for updates

OPEN ACCESS

\section{Introduction}

Doctor-patient relationship is a special type of human relationship that occurs in the clinical encounter between doctor and patient [1]. Probably one of the first studies on the doctor-patient relationship was carried out by Freud [2]. From that moment, and in an exponential way in recent times, this topic has been analyzed [3]. It is within the encounter and the doctor-patient relationship that the diagnosis is made and the treatment is decided. In other words, the doctorpatient relationship is essential for the doctor to carry out the diagnosis and treatment $[4,5]$. And so, it is within that relationship where, very often, the decision to prescribe a drug occurs. This situation is probably especially more frequent in general medicine, where in addition to prescriptions as the end of a diagnosis, there are repeated prescriptions for chronic problems or repeated requests from patients, as well as the so-called derived prescriptions (prescriptions made by another doctor, generally a hospital consultant, who refers the patient to his or her general practitioner (GP) to repeat medications) [6].
There is a certain lack of agreement in the way of understanding and classifying the different types of doctorpatient relationship. But, a key element, that is missing is the current reflection, it is the interference or modification that the prescription of a drug can make on the doctor-patient relationship, which is something common in consultations.

It is classically admitted that the GP is itself a drug; he is the "doctor-drug". The doctor-patient relationship itself has a therapeutic action. In other words, the relational context that the doctor creates in his care of the patient is itself a drug. The relationships and communications that he establishes with patients in the office work like a drug. The creation of this therapeutic context is the result of the doctor-patient relationship strategies in the course of the clinical interview for the diagnosis. Be it paternalistic, persuasive, or patientcentered communication, etc., these strategies are "creating a therapeutic context" (or anti-therapeutic) [7]. Sometimes the relationship between doctor and patient is difficult or problematic; in these cases the "medicine" does not achieve 
the expected results. This "drug called doctor" is powerful and can have many side effects. You have to know how to dose and prescribe it [8].

This therapeutic context has been reported to induce biomedical processes in the patient's brain that may enhance or reduce the effects of chosen interventions. The context thus works as a drug, with real effects and side effects [9], and it must be remembered that the nocebo-placebo effect is also included here $[10,11]$.

A pharmacological prescription whose decision is expressed by the doctor with great confidence, usually has a placebo effect; On the contrary, if the decision is considered of doubtful effect, it will frequently give rise, depending on the general context of the consultation and the personality characteristics of the patient, to a nocebo effect, with poor therapeutic results or pharmacological adverse effects (not chemically mediated, but psychosocially) $[12,13]$. Thus, when the general practitioner prescribes a drug, he should modify his "psychotherapy" or advice according to the patient's pharmacological treatment; It is not appropriate to apply the same techniques -cognitive-behavioral in general- both in patients without drugs and with drugs [14].

On the other hand, the repeated prescription of drugs, in chronic problems or by reiteration of the patient's demand, or by the prescription derived from a hospital consultant, and carried out by computer or electronic means, specifically modifies the doctor-patient relationship. This type of relationship symbolizes a "failure", a "peaceful but hopeless" continuity, which maintains a status quo, but where both doctor and patient are defeated. It is a "tolerable but cold" doctor-patient relationship that is maintained for years, but with the conflicts of the problem always latent. Here, the effect of the "doctor itself as a drug" is very small, "homeopathic", or almost non-existent; the patient comes only to "repeat her prescription", not to make a consultation. In addition, the patient usually considers his repeated drugs as "his or her right", and demands them thoughtlessly, and the doctor also prescribes them out of inertia. Any drug change, dose modification, or withdrawal is troublesome. All this modifies the doctor-patient scenario and makes it difficult for the interpersonal relationship can go something beyond the superficial routine [8].

In this scenario, this brief article, which is a personal vision based on the author's experience and on an opportunistic or non-systematic bibliographic review, aims to reflect and systematize some concepts about the effects of pharmacological prescription, especially of psychoactive drugs, on the doctor-patient relationship and its effects on the results of medical interventions.

\section{Methods}

For the literature review, a pragmatic approach was used that was based on a non-systematic or opportunistic narrative review considered the bibliographic references of selected articles and opportunistic searches on the Internet. A systematic review was not performed, and consequently no structured checklist (such as the PRISMA statement) has been used. This article should be understood as a personal view, based on the author's experience and the literature review as described above.

\section{Discussion}

The bilateral relationship between distress and brain biochemical changes; Medical model vs. biopsychosocial

There is a well-established approach in medicine that says that if the symptoms of a disease are effectively eliminated, it can be assumed that the disease is being treated. This approach leads clinicians towards symptomatic treatment, which is more accessible and tangible than the internal experience of the patient. That is, to the prescription of psychotropic drugs. Obviously this vision is more typical of the mental health sphere, but it can rationally be extended to all the health problems attended by the GP.

Emotional distress leads to biochemical changes in the brain and thus thoughts, feelings and behaviors are biochemically mediated. However, the medical model assumes that it happens the other way around, and that changes in thoughts, feelings, and behaviors are they caused by biochemical changes, and therefore, drug treatment will lead to improved distress.

This bilateral relationship between distress and chemistry assumes that the external factors of life experience, relationships and events could be mitigated by the change in the psychological state of the patient. For example, a person with a certain range of symptoms may take steps to avoid them. Drugs change brain chemistry, decrease symptoms, reduce anxiety, and consequently affect a person's thoughts, feelings, and behaviors. It is assumed that the person can therefore more effectively control his problem once his symptoms have been eliminated. The underlying assumption is not that the symptoms are an inappropriate or undesirable state, but that they do not have deep meaning.

In the bio-psycho-social model, symptoms are assumed to be something in relation to the person's life. In addition, from this perspective, the disorder itself can be therapeutic, since the appearance of signs of distress, such as symptoms and changes in mood and behavior, which are caused in the individual, make him adjust his understanding of the self, his interpersonal relationships, or his life (Figure 1).

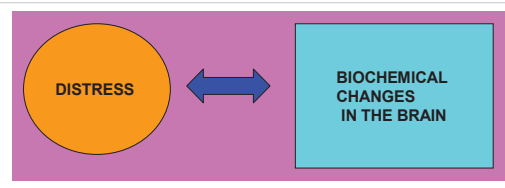

Figure 1: The bilateral relationship between distress and brain biochemical changes. 
Obviously, these models lead to different conclusions about the therapeutic options. In the medical model, the general practitioner (and the psychiatrist) sees the prescription of one or more drugs as mandatory, and is the resolution of the problem or distress the objective of drug treatment. In the biopsychosocial model, the GP and the psychiatrist recognize that feelings of emotional distress can be appropriate, unavoidable, and even acceptable, especially for a limited time.

The approach to the epidemiological chain of causality, in the medical model, is done on biochemical mechanisms through which all biopsychological processes are mediated, and the disease is seen as an imbalance that must be restored with drugs and leads to the idea that some people have to take drugs for the rest of their lives to maintain this balance. The need to confront internal psychological reality is also neglected.

\section{Taking psychotropic drugs blocks the results of psychotherapies}

The truth is that any pharmacological prescription (or deprescription) changes the doctor-patient relationship [3], and psychotropic drugs are a particular case with a special impact. The fact of taking drugs (especially psychotropic drugs and chronically repeated drugs) modifies the results of the educational counselling or the different psychotherapies; In other words: they can make the results of advice, counselling and psychotherapies very difficult, due to changes in thought, emotions and behaviors, mediated by the non-chemical psychosocial effects, but additive to the pharmacological ones, produced by the drugs [14] (Figure 2).

Thus, when the GP or psychiatrist prescribes one or more drugs, he must be aware that he is modifying his relationship with the patient, and that consequently he must re-tune that doctor-patient relationship so that "psychotherapy" or advice or psychopsocial effect that occurs within it is adequate and useful. Drugs can make the effect of the doctor in him as a drug more difficult, and favor an insignificant relational context, where the doctor does not delve into the true meaning of the symptoms, and the patient tends not to get involved, and to make an emotional withdrawal being passive before the prescribed drug $[14,15]$.

The patient who has been treated with psychotropic drugs and the symptoms of it have been alleviated, will

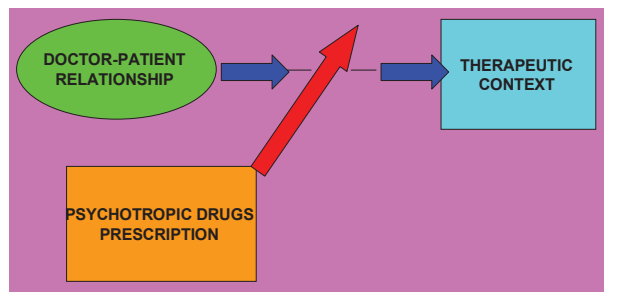

Figure 2: Psychotropic drugs prescription block the positive effects of the doctorpatient communication and relationship. be more reticent, or will be less motivated to seek real and possibly more painful solutions. For example, prescribing benzodiazepines for insomnia will make finding the cause of insomnia more difficult. And so this concept is equally applicable for a great variety of symptoms.

In general terms, drug treatment is aimed at changing the biochemistry and symptoms and consequently the mood, while counselling or psychotherapy that is produced from the appropriate doctor-patient relationship, works from the patient's inner world to change the experience and perception of the health problem, and consequently eliminate the symptoms.

Symptoms are a focus of attention as they somehow indicate inner conflict or evidence that defensive systems have been activated. Symptoms are also the way in which the patient defines her problem: a way of making something accessible or available to someone. The patient may begin by describing her physical symptoms rather than saying how she feels. Physical symptoms can often be expressed through metaphors even though the patient is not fully aware of it. Symptoms appear in sets that collectively have special meaning. If symptoms can be easily understood in terms of being caused by or related to some experience or event, they can be tolerated even if they are severe.

Understanding the meaning of the symptoms provides the GP and the psychiatrist a way of accessing the problem that the patient brings up. Symptoms take on meaning in context, and can be seen as a form of silent communication with others [16]. It may be important for the patient to hold on to her symptoms as a way of defining himself, and until a broad sense of self is established, when attempting to eliminate symptoms they may still worsen. This is the reason why sometimes drugs, which are symptomatic treatment, often make the situation worse. GPs who work with patients taking drugs need to be more active to allow access to patients' feelings.

\section{From the doctor-patient relationship to the drug-patient relationship}

In this scenario, a dramatic and incorrect transformation of the doctor-patient relationship in general medicine and psychiatry is taking place. By prioritizing drug prescription over the interpersonal relationship (or in other words, the biomedical model vs. the bio-psycho-social model), the doctorpatient relationship becomes exclusively in a pharmacological relationship: patient-drug relationship, or "drug dealer doctor"-patient relationship; where the doctor himself as a drug is excluded. This impersonal model of care can be readily accepted by the GP, because medications are used to avoid being with people, and being a doctor as a drug dealer is easier than showing ourselves to be human $[17,18]$.

\section{Conclusion}

In summary, that the GP or psychiatrist understands the 
psychosocial effects of prescribing on the doctor-patient relationship is as important if not more than knowing the pharmacology. Psychotropic drugs act on symptoms and change thoughts, feelings and behaviors; they can create both physical and psychological dependency; they can discourage a deep search for real solutions, both on the part of the doctor and the patient; they can affect the doctor's access to the patient and the problem will be out of their reach. Drugs can make more difficult the effect of the doctor in himself as a drug, favour an insignificant or problematic or not very human relational context, where the GP does not delve into the true meaning of the symptoms, and the patient tends not to get involved, to to make an emotional withdrawal, to be passive before the prescribed drug, and can result in the chronification and structuring of functional symptoms that become organic. It is necessary to reflect in clinical practice on the different "logics" or explanatory models or ways of understanding the disease (especially psychiatric, and mainly depression/ anxiety), and on the need for a comprehensive and adequate approach that allows understanding the dynamics of the disease and establish diagnostic and management strategies in general medicine and psychiatry that do not increase risks in the medium term.

\section{References}

1. Pellegrino ED. The internal morality of clinical medicine: a paradigm for the ethics of the helping and healing professions. J Med Philos. 2001; 26: 559-579.

PubMed: https://www.ncbi.nlm.nih.gov/pubmed/11735050.

2. Pérez Cicili A, Vidaillet Calvo EC, Carnot Pereira J, Duane Machado OJ. The physician-patient relation in the National Health System]. [Article in Spanish]. Rev Cubana Med Gen Integr. 2003; 19. http://scielo.sld.cu/ scielo.php?script=sci_arttext\&pid=S0864-21252003000600006

3. Turabian JL. Drug Prescription Modifies the Doctor-Patient Relationship in General Medicine. Arch Fam Med Gen Pract. 2018; 3: 66-69. https:// scholars.direct/Articles/family-medicine/afmgp-3-012.pdf

4. Turabián Fernández JL, Pérez Franco $B$. The concept of treatment in familiy medicine: A contextualised and contextual map of a city hardly seen]. [Article in Spanish]. Aten Primaria. 2010; 42: 253-254. http:// www.elsevier.es/es-revista-atencion-primaria-27-articulo-el-conceptotratamiento-medicina-familia-S0212656710000259

5. Turabián Fernández JL, Pérez Franco B. [The Effect of Seeing the Sea for the First Time. An Attempt at Defining the Family Medicine Law: The Interview is Clinical Medicine. Aten Primaria. 2008; 40: 565-566. http://www.elsevier.es/es-revista-atencion-primaria-27-articulo-elefecto-ver-primera-vez-mar-un-13128570

6. Turabián Fernández JL, Pérez Franco B. Impact of the induced prescription on the doctor-patient relationship]. [Article in Spanish]. Rev Calid Asist. 2011; 26: 67-69. https://www.elsevier.es/es-revistarevista-calidad-asistencial-256-articulo-impacto-prescripcion-inducidasobre-relacion-S1134282X10001405

7. Turabián JL, Pérez Franco B. Community Activities in Family Medicine and Primary Care. Madrid: Díaz de Santos. 2001; https://www.amazon. es/Actividades-comunitarias-medicina-atenci\%C3\%B3n-primaria/ $\mathrm{dp} / 8479784741$

8. Balint M, Hunt J, Joyce D, Marinker M, Woodcock J. Treatment or diagnosis. A study of repeat prescriptions in general practice. London: Tavistock Publications. 1984.

9. Lucassen P, Olesen F. Context as a drug: some consequences of placebo research for primary care. Scand J Prim Health Care. 2016; 34: 428-433.

PubMed: https://www.ncbi.nlm.nih.gov/pmc/articles/PMC5217288/.

10. Leigh $H$, Reiser MF. The patient. Biological, psychological, and social dimensions of medical practice. Plenun Medical Book Company. 1992.

11. Turabian JL. Contextual treatment: a conceptualization and systematization from general medicine. Int J Fam Commun Med. 2018; 2: 97-104. https://pdfs.semanticscholar.org/f1ec/131f2f26d97e931f5494 371196b8b7a86ee4.pdf?_ga=2.118895553.955135408.1539260497203874004.1539260497

12. Gutiérrez-Islas, Báez-Montiel BB, Turabian JL, Bolaños-Maldonadoa $M$, Herrera-Ontañón JR, et al. Patients with adverse drug reactions have a higher prevalence of emotional disorders. Aten Primaria. 2012; 44: 720-726. http://www.elsevier.es/es-revista-atencion-primaria-27articulo-los-pacientes-con-reacciones-adversas-S0212656712003058

13. Turabian JL, Moreno-Ruiz S. The fable of the pine and the palm tree: the two extremes. Strategies to maximize the placebo effect and minimize the nocebo effect in primary health care. Ment Health Addict Res. 2016; 1: 44-46. https://oatext.com/The-fable-of-the-pine-andthe-palm-tree-the-two-extremes.-Strategies-to-maximize-the-placeboeffect-and-minimize-the-nocebo-effect-in-primary-health-care.php

14. Hammersley D. Counselling people on prescribed drugs. London: Sage Publications. 1995.

15. Turabian JL. Doctor-Patient Relationship in Pharmacological Treatment: Discontinuation and Adherence. COJ Rev Res. 2018; 1. https://crimsonpublishers.com/cojrr/pdf/COJRR.000521.pdf

16. Turabian JL. Interpretation of the Reasons for Consultation: Manifest and Latent Content. the Initiation of the Diagnostic Process in General Medicine. Archives of Community and Family Medicine. 2019; 2. https://www.sryahwapublications.com/archives-of-community-andfamily-medicine/pdf/v2-i1/1.pdf

17. Durif-Bruckert $C$, Roux $P$, Rousset $H$. Medication and the patientdoctor relationship: a qualitative study with patients suffering from fibromyalgia. Health Expect. 2015; 18: 2584-2594.

PubMed: https://www.ncbi.nlm.nih.gov/pubmed/24995371.

18. Turabian JL. The Wrong Transformation of Doctor-Patient Relationship in Drug-Patient Relationship: From the Doctor Himself as A Drug to Doctor as Drug Dealer. Chronicle of Medicine and Surgery. 2018; 3 : 298-301. https://scientiaricerca.com/srcoms/SRCOMS-03-00052.php 